\title{
Reactive Astrocytes As Therapeutic Targets for CNS Disorders
}

\author{
Mary E. Hamby and Michael V. Sofroniew \\ Department of Neurobiology, David Geffen School of Medicine, University of California, Los Angeles, California 90095
}

\begin{abstract}
Summary: Reactive astrogliosis has long been recognized as a ubiquitous feature of CNS pathologies. Although its roles in CNS pathology are only beginning to be defined, genetic tools are enabling molecular dissection of the functions and mechanisms of reactive astrogliosis in vivo. It is now clear that reactive astrogliosis is not simply an all-or-nothing phenomenon but, rather, is a finely gradated continuum of molecular, cellular, and functional changes that range from subtle alterations in gene expression to scar formation. These changes can exert both beneficial and detrimental effects in a context-dependent manner determined by specific molecular signaling cascades. Dysfunction of either astrocytes or the process of reactive astrogliosis is emerging as an important potential
\end{abstract}

source of mechanisms that might contribute to, or play primary roles in, a host of CNS disorders via loss of normal or gain of abnormal astrocyte activities. A rapidly growing understanding of the mechanisms underlying astrocyte signaling and reactive astrogliosis has the potential to open doors to identifying many molecules that might serve as novel therapeutic targets for a wide range of neurological disorders. This review considers general principles and examines selected examples regarding the potential of targeting specific molecular aspects of reactive astrogliosis for therapeutic manipulations, including regulation of glutamate, reactive oxygen species, and cytokines. Key Words: Reactive astrocyte, astrogliosis, inflammation, injury, repair.

\section{INTRODUCTION}

Astrocytes are specialized glial cells that are ubiquitous throughout all regions of the CNS. Astrocytes outnumber neurons by more than fivefold and contiguously tile the entire CNS in an essentially uninterrupted manner. Although neurons have long been the focus of attention as mediators of CNS functions, an ever-growing body of evidence indicates that astrocytes and other glia play primary roles in neural processing in both health and disease. Astrocytes play essential roles in normal, continually ongoing CNS functions, including regulation of blood flow, provision of energy metabolites to neurons, participation in synaptic function and plasticity, and maintenance of the extracellular balance of ions, fluid balance, and transmitters (as reviewed in detail elsewhere ${ }^{1-5}$ ). In addition, astrocytes respond to all forms of CNS insult, such as infection, trauma, ischemia, and neurodegenerative disease, by a process commonly referred to as reactive astrogliosis, which involves changes in astrocyte molecular expression and in severe

\footnotetext{
Address correspondence and reprint requests to: Michael V. Sofroniew, M.D., Ph.D., Department of Neurobiology, David Geffen School of Medicine, University of California, Los Angeles, CA 900951763. E-mail: sofroniew@mednet.ucla.edu.
}

cases results in scar formation (reviewed in detail elsewhere ${ }^{6,7}$ ).

Reactive astrogliosis is not merely a marker of neuropathology, but plays essential roles in orchestrating the injury response, as well as in regulating inflammation and repair in a manner that markedly affects functional and clinical outcomes. ${ }^{5,7,8}$ Enormous progress has been made in characterizing molecular mechanisms underlying astrocyte and reactive astrocyte functions, and a vast molecular arsenal at the disposal of astrocytes and reactive astrocytes is being defined. Accordingly, astrocytes and reactive astrocytes are increasingly recognized as potential targets for novel therapeutic strategies for a variety of CNS conditions. ${ }^{7,9-11}$ Here we review recent findings and consider general principles regarding the potential of targeting reactive astrogliosis for therapeutic manipulations, with a focus on a number of specific molecular mechanisms as examples.

\section{GENERAL APPROACH TO REACTIVE ASTROCYTES AS THERAPEUTIC TARGETS}

In considering the potential for reactive astrocytes as therapeutic targets, it is useful first to examine their characteristics, functions, and molecular mechanisms. Concepts of the functions and effects of reactive astro- 
gliosis have long been dominated by the 100-year-old recognition that scars formed by reactive astrocytes inhibit axon regeneration and by the interpretation that this scar is the main impediment to functional recovery after CNS injury or disease. These observations have sometimes led to the simplistic notion that reactive astrogliosis is an all-or-nothing maladaptive process synonymous with scar formation and that the total inhibition of reactive astrogliosis could be regarded as a therapeutic strategy. This absolutely negative view of reactive astrogliosis is no longer tenable, and it is clear from a growing body of experimental evidence that there is a normal, adaptive process of reactive astrogliosis, including scar formation, which exerts essential beneficial functions. ${ }^{5,7,8}$ These studies have shown that reactive astrogliosis is not a simple, all-or-nothing phenomenon, nor is it ubiquitously synonymous with scar formation. Instead, reactive astrogliosis is a finely gradated continuum of changes that occur in response to all CNS insults in a context-dependent manner regulated by specific signaling events. ${ }^{7}$

In reactive astrogliosis, the continuum of changes ranges from reversible alterations in gene expression and cell hypertrophy with preservation of cellular domains and tissue structure after mild insults to long-lasting scar formation with permanent rearrangement of tissue structure after severe insults. ${ }^{5,7,8}$ The changes effected during reactive astrogliosis have the potential to alter astrocyte activities through both gain and loss of functions that can affect surrounding neural and non-neural cells both beneficially and detrimentally. ${ }^{5,7,8}$ Because astrocytes and reactive astrocytes have the potential to influence essentially all aspects of neural function through the regulation of blood flow and provision of energy substrates, or by influencing synaptic function and plasticity, it is perhaps not surprising that dysfunction of the processes underlying reactive astrogliosis and scar formation has the potential to contribute to, or even be the primary cause of, CNS disease mechanisms, either through loss of normal functions or through gain of detrimental effects. ${ }^{5,7}$

Numerous studies using transgenic and experimental animal models provide compelling evidence that reactive astrocytes protect CNS cells and tissue in multiple ways that involve a variety of different molecular mechanisms, including i) uptake of potentially excitotoxic glutamate, ${ }^{12-14}$ ii) protection from oxidative stress via glutathione production, ${ }^{14-18}$ iii) neuroprotection via adenosine release, ${ }^{19}$ iv) protection from $\mathrm{NH}_{4}{ }^{+}$toxicity ${ }^{20} \mathrm{v}$ ) neuroprotection by degradation of amyloid- $\beta$ peptides, ${ }^{21}$ vi) facilitation of blood-brain barrier repair, ${ }^{13}$ vii) reduction of vasogenic edema after trauma, stroke, or obstructive hydrocephalus, ${ }^{13,22}$ viii) stabilization of extracellular fluid and ion balance thereby increasing seizure threshold, ${ }^{22}$ and ix) limiting the spread of inflammatory cells or infectious agents from areas of tissue damage or disease into healthy CNS parenchyma. ${ }^{13,23-29}$ Nevertheless, it is also clear that reactive astrocytes can also play harmful roles during injury or disease through gain of abnormal effects such as overproduction of reactive oxygen species (ROS) or certain inflammatory cytokines. ${ }^{5,7,14}$ Thus, overall, reactive astrocytes have the potential to influence injury and disease outcomes both positively and negatively, as determined by specific signaling events and molecular effector mechanisms. . $^{5,8}$

Taken together, observations from experimental animal studies indicate that the global inhibition or ablation of reactive astrogliosis is not likely to be a useful therapeutic approach and that in most situations it has the potential to do more harm than good. ${ }^{5,7,8}$ Instead, therapeutic strategies should be directed at more specific astrocyte functions or at specific aspects of reactive astrogliosis, by targeting astrocyte-related molecular mechanisms. Considerable progress has been made in identifying the molecular mechanisms that regulate specific aspects of reactive astrogliosis or that are involved in mediating its functions and effects. ${ }^{5,7}$ Some of these molecules will be common to many cells (e.g., cytokines, ROS), whereas other molecules will be selective to astrocytes and may be targetable selectively (e.g., astrocyte glutamate transporters, SOD1).

In the sections that follow, we consider a number of molecules related to astrocytes and reactive astrogliosis and discuss their potential, and in some cases on-going development, as therapeutic targets for specific CNS disorders. Space constraints limit consideration to a crosssection of representative candidate molecules.

\section{SPECIFIC POTENTIAL MOLECULAR THERAPEUTIC TARGETS RELATED TO ASTROCYTES AND REACTIVE ASTROGLIOSIS}

\section{Glutamate transmission and excitotoxicity}

Astrocyte processes that envelope synapses express high levels of transporters for the amino acid neurotransmitter glutamate. These transporters clear the glutamate from the synaptic space; after uptake into astrocytes, the glutamate is converted by glutamine synthetase into glutamine and recycled back to synapses for reconversion to the active transmitter, glutamate. ${ }^{30,31}$ Through these transporters, astrocytes play essential roles in regulating extracellular levels of glutamate, which puts astrocytes in a position to reduce the potential for excitotoxicity. Indeed, genetic animal models have shown that loss of astrocytes or attenuation of astrocyte glutamate transporters such as EAAT1 and EAAT2 can lead to excitotoxic neurodegeneration. ${ }^{12,13}$

The expression or activity of astrocyte glutamate transporters is subject to a high degree of regulation both transcriptionally and post-transcriptionally. ${ }^{30-33}$ Gluta- 
mate transporter activity is reduced in various neurodegenerative conditions such as amyotrophic lateral sclerosis (ALS). ${ }^{34}$ Thus, modulation of EAAT1 and EAAT2 represents pharmacological targets that may modify neuronal function or protect neurons by manipulating glutamate levels. ${ }^{9,30}$ For example, augmenting the function of the astrocyte glutamate transporter EAAT2 with parawexin 1, a molecule isolated from spider venom, has been shown to protect retinal neurons from ischemic degeneration by enhancing glutamate uptake and thereby reducing the potential for glutamate excitotoxicity. ${ }^{35,36}$ A high-throughput screen of small molecules has identified that certain $\beta$-lactam antibiotics can enhance astrocyte-mediated glutamate uptake sufficiently to provide neuroprotection in models of stroke and ALS by stimulating the expression of astrocyte glutamate transporters and thereby reducing excitotoxicity. ${ }^{37}$ In 2010 , the $\beta$-lactam antibiotic ceftriaxone was in phase III clinical trials to determine efficacy in reducing excitotoxicity and neurodegeneration in ALS. Finally, a noncompetitive blocker of the AMPA glutamate receptor, talampanel, is also in clinical trials for ALS, with phase II just completed. $^{38}$

An additional potential target for manipulating astrocyte influences on glutamatergic synaptic transmission is astrocyte calcium signaling. Astrocytes exhibit transient elevations of cytosolic calcium levels in response to activation of a number of different membrane receptors; these calcium transients are regarded as a form of astrocyte excitability. ${ }^{39-41}$ Although the precise roles and mechanisms of astrocyte calcium signaling are incompletely understood, calcium transients in astrocytes have been shown to affect neuronal excitatory transmission, including network properties such as the ability to induce long-term potentiation. ${ }^{42,43}$ In this regard, it is particularly interesting that receptor selectivity has been noted, such that calcium transients triggered in astrocytes by activation of PAR-1 receptors led to the appearance of NMDA receptor-mediated slow inward currents in hippocampal pyramidal neurons, whereas calcium transients triggered in astrocytes by activation of $\mathrm{P} 2 \mathrm{Y} 1$ receptors did not. $^{44}$

\section{Enzymes and scavengers related to oxidative stress}

NOS-2. Nitric oxide synthase-2 (NOS-2 or iNOS) is the inducible and calcium-independent isoform of NO synthase, the enzyme responsible for the production of the free radical NO. Whereas under normal physiological conditions NOS-2 is not expressed, it is induced due to injury or inflammation by a variety of stimuli, including interleukin $1 \beta$ (IL-1 $\beta$ ), lipopolysaccharide (LPS), and tumor necrosis factor $\alpha$ (TNF $\alpha)$ in both astrocytes and microglia. ${ }^{45-49}$ In several rodent models, there is evidence that NOS-2 expression or activity contributes to neurological injury and disease. ${ }^{50-56}$ For example, inhi- bition of NOS-2 activity ${ }^{57}$ or genetic deletion of NOS-2 in mice subjected to a middle cerebral artery occlusion ${ }^{53}$ have reduced infarct volumes, compared with wild-type controls. Furthermore, transgenic mice modeling Alzheimer's disease (i.e., hAPP-hPS1-double transgenic mice) were found to have reduced Alzheimer's disease-associated pathology when crossed with mice lacking NOS$2 .^{58}$ These mice exhibited reduced $\beta$-amyloid plaque formation, attenuated gliosis and notably had an increased lifespan, compared with that bred with NOS$2^{+/+}$mice. $^{58}$

Other evidence suggests that NOS-2 induction may be beneficial in certain instances, ${ }^{59-62}$ including expression of astrocyte-specific NOS-2. ${ }^{61,62}$ In this regard, note that although one study found NOS-2 to contribute to Alzheimer's pathology in hAPP-hPS1-double transgenic mice, ${ }^{58}$ different results were obtained when using a different transgenic mouse model of Alzheimer's disease, the Swedish familial double mutation APP (i.e., APPsw). When APPsw mice were crossed onto a NOS2 ${ }^{-I-}$ background, the offspring exhibited increased Alzheimer's disease-associated pathology, including hyperphosphorylation of tau and increased levels of insoluble $\beta$-amyloid, along with an increase in neuronal degeneration, compared with APPsw mice on a $\mathrm{NOS}^{+/+}$ background. ${ }^{60}$ These observations suggest that NOS-2 may have positive and negative consequences in Alzheimer's disease, depending on the nature of the pathological etiologies.

Although the specific molecular mechanisms underlying the outcomes of NOS-2 induction in vivo remain largely elusive, several mechanisms have been established in vitro. It has been well-documented in a host of cells throughout the body that NOS-2-derived NO can contribute to cell death through the depletion of cellular energy sources by causing DNA strand breaks and by inhibiting mitochondrial respiration, among other mechanisms. ${ }^{63,64}$ Given the close apposition of astrocytes to the neuronal synapse, one putative role for an astrocytemediated effect of NOS-2-derived NO is in the modulation of neuronal glutamate activity. In support, astrocytespecific NOS-2-derived NO has been shown to enhance NMDA-dependent neuronal cell death through synaptic glutamate release. ${ }^{46,65,66}$ At higher concentrations of NO, however, astrocytic NOS-2-derived NO may play a role in preventing excitotoxic cell death. In support, in astrocyte neuronal co-cultures addition of NO donors that released high concentrations of NO resulted in protection of NMDA-dependent excitotoxicity, an effect that was paralleled by a concentration-dependent reduction in NMDA channel activity. ${ }^{61,62}$ Given the intimate association of astrocyte end-feet with the vasculature and the known role of $\mathrm{NO}$ as a potent vasodilator, ${ }^{67}$ astrocytic NOS-2-derived NO might be instrumental in increasing blood flow in times of need (e.g., by increasing 
oxygen extraction and in providing the proper energy sources needed during cellular repair).

Overall, evidence suggests that astrocyte-specific NOS-2 may be an important target for designing therapies for neurological diseases and disorders. Because NOS-2 can also be induced in microglia, it is critical that studies continue to elucidate the cell-type-specific regulation of NOS-2.

$\mathrm{Cu} / \mathrm{Zn}$ superoxide dismutase (SOD). Mutations in $\mathrm{Cu} / \mathrm{Zn}^{2}$ superoxide dismutase (SOD) are the primary cause of familial ALS. Although, the precise mechanisms contributing to the disease are still unclear, numerous mechanisms, including oxidative stress and excitotoxicity, are thought to contribute to this disease. ${ }^{68,69}$ A large body of evidence suggests that astrocytes play an important role in the disease process. In a mouse model of ALS, reduced expression of dominantly inherited mutant SOD (G37R mutation) selectively in astrocytes of the brain through Cre-lox site-specific recombination resulted in delayed microglial activation and slowed late disease progression resulting in increased lifespan. ${ }^{70}$ Notably, this implicated a sole molecule in astrocytes as mediating non-cell-autonomous neuropathology. Although the mechanism to explain how the decrease in astrocyte mutant SOD affects microglial reactivity and increases the survival of these mice is unknown, a robust reduction in astrocyte glutamate transporter GLT-1 expression was evident in both the motor cortex and spinal cord of ALS patients, ${ }^{71}$ as well as in transgenic SOD-1 mutant mouse models. ${ }^{72}$ Thus, devising therapies aimed at targeting mutant SOD in astrocytes may hold therapeutic promise for patients with inherited ALS. Along these lines, a transplantation-based replacement of astrocytes is reported to be neuroprotective in a mutant SOD1 transgenic mouse model of ALS. ${ }^{73}$ Overall, these studies highlight the potential benefits that targeting astrocytes for therapeutic purposes, especially in ALS, may provide.

COX-2. The therapeutic potential, as well as preventative potential, of nonsteroidal anti-inflammatory inhibitory drugs (NSAIDs) in neurological diseases and disorders has been reviewed in great detail. ${ }^{74}$ NSAIDs act to inhibit cyclooxygenases 1 and 2 (COX-1 and COX-2), enzymes that have various critical functions, through prostaglandin production, in regulating blood flow as well as inflammatory pathways. In addition, NSAIDS are now known to have additional targets, including NF- $\kappa \mathrm{B}, \mathrm{AP}-1$ and NOS among others (for review, see Lleo et al. ${ }^{74}$ and Asanuma and Miyazaki ${ }^{75}$ ). Treatment with NSAIDS in mouse models leads to diminished reactive astrogliosis, as evidenced after administration of ibuprofen in a transgenic model of Alzheimer's disease (APPV717I ${ }^{76}$ and of celecoxib in a transgenic model of ALS, ${ }^{77}$ but it is not clear whether these are direct effects on astrocytes or indirect effects on other mechanisms that may in turn be responsible for astrocyte reactivity. In vitro studies have demonstrated that the NSAID acetylsalicylic acid abrogates both NF- $\kappa \mathrm{B}$ activity and the upregulation of glial fibrillary acidic protein (GFAP) induced by hypoxia in a human astroglial cell line. ${ }^{78}$ Whether any of the beneficial effects of NSAIDs in vivo work directly through astrocytes, however, remains unclear and requires further investigation.

Glutathione. Astrocytes are the predominant source of glutathione (GSH) in the CNS, ${ }^{79}$ and astrocyte-derived GSH plays important roles in protecting neurons from oxidative stress. ${ }^{14,15}$ Astrocyte GSH levels are influenced by cytokine signaling pathways associated with regulating specific aspects of astrogliosis; for example, disruption of STAT3 signaling in astrocytes markedly attenuates GSH levels and increases oxidative stress. ${ }^{18}$ $S$-nitrosoglutathione has been identified as a molecule produced by enteric astroglia that has mucosal barrier inducing functions. ${ }^{80,81}$ The roles of astroglial-derived $S$-nitrosoglutathione in the CNS have not yet been adequately explored. Modulating GSH production by reactive astrocytes is an interesting potential target for neuronal protection from oxidative stress in both acute and chronic CNS disorders. ${ }^{9,10}$

\section{Cytokine and growth factor signaling}

Astrocytes can both secrete and respond to a number of important cytokines affecting the cellular state both of surrounding cells, such as microglia and neurons, and of astrocytes themselves. For example, cytokines such as IL- $1 \beta$, TNF $\alpha$, IL-6, and transforming growth factor- $\beta 1$ (TGF- $\beta 1$ ) can act to upregulate or downregulate other pro- and anti-inflammatory genes including NOS-2 and COX-2. ${ }^{45,82-86}$ Astrocytes also play a important role in the secretion of trophic factors such as glial cell linederived neurotrophic factor (GDNF), brain-derived neurotrophic factor (BDNF), nerve growth factor (NGF), and basic fibroblast growth factor (bFGF). Through the secretion of various growth factors, astrocytes can promote neuronal and oligodendrocyte survival, ${ }^{87-91}$ as well as promote myelination in mature oligodendrocytes. ${ }^{92}$ Thus, targeting the astrocyte in a way to promote growth factor release or to modulate cytokine release (up or down) is very much an important area of study. In this section, we will focus on some of the better characterized signaling pathways with respect to astrocytes and neurological diseases and disorders.

TGF- $\beta 1$ and SMAD3 signaling. Transforming growth factor- $\beta 1$ is a pleiotropic cytokine normally expressed at low to undetectable levels in the brain, but it is strongly upregulated under neuropathological conditions in a great variety of neurological diseases and disorders. ${ }^{93-109}$ TGF- $\beta 1$ signals by binding to TGF $\beta$ RII, which then heterodimerizes and transphosphorylates the 
TGF $\beta$ signaling receptor TGF $\beta$ RI, either activin-like kinase 5 or 1 (ALK5, ALK1), initiating an intracellular serine/threonine kinase signaling cascade. ${ }^{110}$ Whereas ALK1 phosphorylates SMAD1/5/8, ALK5 phosphorylates SMAD2/3, each resulting in nuclear translocation of distinct signaling complexes producing disparate changes in gene expression. ${ }^{110}$

The effects of TGF- $\beta 1$ in the brain are widespread and appear to be context-dependent with respect to the disease or disorder examined. An extensive literature has clearly demonstrated a neuroprotective role of TGF- $\beta 1$ in a variety of in vivo (i.e., middle cerebral artery occlusion) and in vitro (i.e., excitotoxic) models of cerebral ischemia. ${ }^{11-116}$ Other studies, however, show a proinflammatory and neuropathological role for TGF- $\beta 1$, which has been especially well documented in the case of Alzheimer's disease in both in vivo and in vitro rodent models. ${ }^{117-123}$

Whether any of the roles of TGF- $\beta 1$ in neuroprotection or neuropathology rely on TGF- $\beta 1$ signaling through astrocytes remains elusive. However, TGF- $\beta 1$ is known to have several effects on astrocytes, including effects on gene expression, such as upregulation of amyloid precursor protein (APP), ${ }^{120,122,124}$ modulation of the astrocyte response to pro-inflammatory mediators, ${ }^{45,82}$ and regulation of astrogliosis via increasing GFAP expression, eliciting hypertrophy, and facilitating glial scar formation through upregulation of extracellular matrix molecules (i.e., chondroitin sulfate proteoglycans, fibronectin, laminin). ${ }^{119,124 a}$ Consistent with the effects of TGF- $\beta 1$ on extracellular matrix formation, mice that lack $S m a d 3$, the downstream effector of TGF- $\beta 1$ signaling through ALK5, exhibit a faster rate of wound closure after stab injury to the brain, compared with control mice. $^{125}$

Because all brain parenchymal cells are capable of secreting ${ }^{126}$ and responding ${ }^{107,127-129}$ to TGF- $\beta 1$, it is interesting to note that neurons and endothelial cells are known to signal through both the ALK1 and ALK5 TGF $\beta$ RI receptors. ${ }^{130,131}$ To date, however, astrocytes and microglia are known to express and signal only through the ALK5 TGF $\beta$ RI. ${ }^{132,133}$ This difference in expression alone could prove to be fortuitous, but, in addition, microglia and astrocytes have, at least in part, divergent responses to the cytokine. For example, when NOS-2 is induced in cultured astrocytes upon pro-inflammatory stimulation, expression of NOS-2 and its resultant NO production are attenuated in microglia but are enhanced in astrocytes by TGF- $\beta 1 .^{48,82}$ Although progress has been made in understanding the differential cell-type response to TGF- $\beta 1$ in the brain, future elucidation of regulatory molecules in this pathway should prove to be fruitful.

NF- $\boldsymbol{~ B ~ B ~ s i g n a l i n g . ~ T h e ~ t r a n s c r i p t i o n a l ~ i n d u c t i o n ~ o f ~}$ various inflammatory mediators such as IL- $6^{134}$ and
NOS-2 requires that the transcription factor NF- $\kappa \mathrm{B}$ is activated, translocated into the nucleus, and bound to its cognate NF- $\kappa$ B consensus element. NF- $\kappa$ B can be activated by several pro-inflammatory mediators, including LPS, TNF $\alpha$ and IL- $1 \beta$. The classic endogenous activator, IL- $1 \beta$, is a cytokine that has been implicated in the pathogenesis of numerous neurological disorders, diseases, and injuries (for review, see Fogal and Hewett ${ }^{135}$; for review of the global IL- $1 \beta$-mediated changes in astrocytes and the IL- $1 \beta$-specific signaling cascades in astrocytes, see John et al. ${ }^{136}$ ). Because NF- $\kappa$ B is not specific to astrocytes, identification of astrocyte-specific regulation is warranted. Inhibition of NF- $\kappa \mathrm{B}$ selectively in astrocytes is reported to ameliorate inflammation and to improve the rate of recovery after spinal cord injury. ${ }^{137}$ Evidence suggests that chromatin remodeling may play a critical role in determining whether NF- $\kappa$ B binds to a particular promoter in a given cell type. ${ }^{138-142}$ Given the cell-type-specific nature of epigenetic signatures, elucidation of the epigenetic modifications present in astrocytes will be important in understanding the transcriptional regulation of $\mathrm{NF}-\kappa \mathrm{B}$-dependent genes in astrocytes.

\section{IL-6 and STAT3 signaling}

Interleukin- 6 is a cytokine that can be produced by both glia and neurons of the CNS and can be induced by inflammatory mediators, including IL- $1 \beta, \mathrm{TNF} \alpha$, and LPS. ${ }^{143}$ IL-6 signals through the gp130 receptor, which elicits activation of the JAK/Stat pathway and elicits changes in gene expression mainly through the activation of STAT3. ${ }^{144}$ Interleukin-6 signaling through STAT3 is a known trigger of reactive astrogliosis. ${ }^{7}$ The role of IL-6 can be beneficial or detrimental, depending on the rodent model (e.g., IL-6 overexpressor or IL-6 conditional overexpressor) used and the disease model studied. ${ }^{145-149}$

With regard to astrocytes, STAT3 is an early trigger of astrogliosis. ${ }^{150}$ Indeed, in a mouse model of 1-methyl-4phenyl-1,2,3,6-tetrahydropyridine (MPTP)-induced striatal degeneration, gp130-related cytokines (e.g., IL-6, ciliary neurotrophic factor) were upregulated prior to STAT3 activation in astrocytes (i.e., phosphorylated STAT3 [pSTAT3]) and nuclear translocation, events that preceded the upregulation of GFAP mRNA and protein expression. ${ }^{150}$ Given that the Gfap promoter has STAT3 consensus binding sites known to be required for proper induction of GFAP, ${ }^{151,152}$ the notion of IL-6 signaling through STAT3 as a trigger of astrogliosis, which is hallmarked by an upregulation in GFAP expression, is not surprising. However, not only is STAT3 a trigger of astrogliosis, but it seems to be required for proper astrogliosis to occur, at least in the case of spinal cord injury. ${ }^{153}$ More specifically, astrocyte-specific Stat3 conditional knockout mice have attenuated GFAP expression, diminished astrocyte hypertrophy, and a lack of 
proper glial scar formation, compared with Stat $^{+/+}$ mice. This genetic deletion of Stat3 selectively in astrocytes also resulted in non-cell-autonomous effects, including increased microgliosis and inflammatory cell infiltration, which corresponded to an increase in lesion size following spinal cord injury and resulted in a diminution in motor function recovery. ${ }^{153}$

A recently published study found that triptolide, an active ingredient in the traditional Chinese herb Tripterygium wilfordii Hook. f., was found to reduce astrogliosis in vitro and in vivo. ${ }^{154}$ In both cases, in an astrocyte culture scratch injury model and after spinal cord injury in rat, pSTAT3 levels were reduced in parallel with a decrease in GFAP immunoreactivity. In culture, a decreased number of proliferative cells were present, whereas in vivo a marked reduction in glial scar formation as assessed 4 weeks post-injury was observed. In addition, animals treated with triptolide have improved locomotion function, compared with control spinal cordinjured mice. ${ }^{154}$ However, given that triptolide can affect other cells in an anti-inflammatory fashion, including microglia, ${ }^{155}$ whether the in vivo phenotype of diminished astrogliosis is directly or indirectly mediated by the herb remains unknown. Overall, further study of IL-6 and STAT3 signaling pathways should prove beneficial in the long term.

Other cytokines and growth factors. Astrocytes can express receptors and respond to a large variety of other growth factors and cytokines, including but by no means limited to TNF $\alpha$, EGF, FGF, endothelins, and various interleukins (for reviews, see Sofroniew ${ }^{7}$ and Mena and García de Yébenes ${ }^{91}$ ). These factors can induce the expression of molecules associated with reactive astrogliosis, such as GFAP, or have been implicated in astrocyte proliferation. ${ }^{156,157}$ Space constraints limit detailed consideration here, but some of these factors may come to represent interesting potential therapeutic targets.

\section{Nucleotides and their receptors}

In addition to their many essential intracellular functions, the nucleotides ATP, ADP, and adenosine have functions as extracellular signaling molecules that act through specific plasma membrane receptors, the purinoceptors $\mathrm{P} 2 \mathrm{X}$ and $\mathrm{P} 2 \mathrm{Y}$ and the adenosine receptor (A), all of which have multiple family members. ${ }^{158}$ ATP signaling triggers elevations in cytosolic calcium in astrocytes $^{44,159,160}$ and leads to gene expression changes associated with reactive astrogliosis after trauma-induced cell injury in vitro. ${ }^{161-163}$ The molecular pharmacology of P2X, P2Y, and adenosine involves a number of inhibitors and activators, and some of these are being studied for effects on reactive astrogliosis and CNS injury and repair after traumatic injuries such as spinal cord injury. ${ }^{164,165}$ This is a promising area for future exploration.

\section{Epigenetic regulators}

Epigenetic regulation of gene expression and its role in neurological diseases and disorders is a growing field of potential therapeutic importance. See Urdinguio et al. ${ }^{166}$ for a thorough and recent review of the epigenetic regulation in relation to neurological diseases and disorders. Two putative targets of regulation have been widely studied in recent years, namely histone deacetylases (HDACs) and histone acetyltransferases (HATs). These HATs and HDACs have opposing roles in the acetylation and deacetylation of histones, a dynamic process that can robustly and globally affect gene expression patterns in a cell. ${ }^{166 a}$ HATs and HDACs not only affect histone acetylation patterns, but can modulate transcription factors through acetylation. Moreover, the patterns of genes affected by this process vary among cell types and are context-dependent. Thus, modulation of HAT and HDAC function through pharmacological manipulation could broadly influence astrocyte responses to other signaling molecules and could powerfully modulate astrocyte functions in health and disease.

HDAC inhibitors. Pharmacological inhibition of HDACs results in both an increase in histone acetylation and a decrease in neuropathology and neurological deficits in a variety of animal models of neurological diseases and disorders, including experimental autoimmune encephalomyelitis ${ }^{167}$ and ischemia. ${ }^{168-171}$ Although the exact cellular and molecular targets underlying such beneficial effects of HDAC inhibitors remain unknown, in vivo and in vitro evidence suggests that astrocytes may be important targets. ${ }^{171}$ Astrocytes express various HDACs, and treatment of rodent astrocytes in vitro with HDAC inhibitors, including valproic acid and trichostatin A, results in global and specific histone residue hyperacetylation ${ }^{172}$ and thus changes in gene expression profiles. In astrocytes, several genes have already been shown to be affected by various HDAC inhibitors including the reduction in levels of various pro-inflammatory-related genes, ${ }^{173}$ the upregulation of the glutamate transporter GLT-1 ${ }^{174,175}$ and the enhancement of growth factor secretion (i.e., GDNF and BDNF). ${ }^{171}$ The HDAC inhibitor valproic acid is currently used in treating epilepsy ${ }^{176}$ and is also being tested for cancer. ${ }^{177}$ For further review on the potential of HDAC inhibitors as therapies in neurological diseases and disorders, see Langley et al. ${ }^{178}$ and Kazantsev and Thompson. ${ }^{179}$

The HAT inhibitor curcumin. Curcumin, a major curcuminoid in the spice turmeric, is an inhibitor of the histone acetyltransferase (HAT) $\mathrm{p} 300^{180,181}$; it is currently being investigated in rodent models of neurological disease as a prospective therapeutic option. The effects of curcumin have been generally described as 
having anti-inflammatory and antioxidant properties. Consistent with that, evidence suggests that curcumin reduces clinical severity or improves neurological function in several neurological diseases and disorders and injuries, including experimental allergic encephalomyelitis $^{182}$ and traumatic brain injury (TBI) ${ }^{183}$ in mice and spinal cord injury in rat. ${ }^{184}$ Pathologically, curcumintreated animals subjected to contusional brain injury exhibit reduced edema correlating with a reduction in levels of IL- $1 \beta$ and aquaporin 4 (AQP4), compared with control animals. ${ }^{183}$ Although it is unclear what underlies the beneficial effect of curcumin in these instances, it is clear that curcumin affects astrocytes. In mouse models of autoimmune encephalomyelitis, ${ }^{182}$ spinal cord injury, ${ }^{184}$ and traumatic brain injury, ${ }^{183}$ curcumin-treated animals exhibit reduced astrogliosis, as evidenced by an attenuation in the upregulation of GFAP expression, an effect that appears to be cell-autonomous, in that curcumin also reduces GFAP expression in purified astrocyte cultures. ${ }^{184}$ Treatment of mouse cortical astrocytes with curcumin in vitro also reduces the IL- $1 \beta$-mediated activation of the classic inflammatory mediator NF$\kappa \mathrm{B} .{ }^{183}$ Future studies delineating the roles of curcumin under neuropathological conditions and in the regulation of signaling pathways and gene expression profiles in astrocytes should be worthwhile.

\section{Other astrocyte-specific molecules and regulators}

Aquaporin 4. A water channel protein responsible for bidirectionally transporting water to and from the blood and the brain, AQP4 is normally localized on astrocyte end-feet. The expression levels and localization of AQP4 in astrocytes are subject to much regulation. During inflammatory conditions, for example, AQP4 is subject to upregulation by cytokines such as IL-1 $\beta .{ }^{183}$ Dysregulation of AQP4 expression or function can lead to brain edema. ${ }^{185,186}$ Mice lacking Aqp4 exhibit decreased brain edema that corresponds to a decrease in astrocyte end-feet swelling following cerebral ischemia or acute water intoxication. ${ }^{185}$ AQP4 expression is elevated in animal models of hydrocephalus, an effect that seems to be productive, given that both edema clearance and survival are decreased in mice that lack Aqp4. ${ }^{187}$ Given the large number of known regulators for AQP4, including arginine-vasopressin, which can activate AQP4-mediated radial water transport across the astrocyte syncytium, ${ }^{188}$ it will be important to continue to study the regulation of AQP4 and to test whether manipulation of this channel proves useful in the treatment of various diseases involving brain edema. For review of AQP4 function in astrocytes in greater detail, see Seifert et al. $^{4}$ and Nag et al. ${ }^{189}$

It is also important to note that AQP4 is now established as the target antigen in the CNS autoimmune demyelinating inflammatory disorder neuromyelitis op- tica. ${ }^{190,191}$ Neuropathological evaluations in neuromyelitis optica are consistent with a mechanism whereby autoimmune destruction of astrocytes triggered by binding of AQP4 autoantibodies leads to inflammatory cell invasion and destruction of neural parenchyma. ${ }^{192-194}$ These neuropathological findings are in line with and are supported by a large body of work in experimental animals showing that astrocytes are essential regulators that restrict inflammatory cell infiltration into CNS parenchyma and protect neural tissue during both innate and adaptive immune inflammation. ${ }^{7,13,23,194,195}$ Interventions that reduce autoimmune recognition of AQP4 and thereby reduce consequent astrocyte dysfunction and damage represent important therapeutic targets.

Connexin gap junctions. Astrocytes are highly connected to one another by homologous connexin 43 (Cx43) gap junctional coupling, forming what is known as the glial syncytium, in which interglial communication (e.g., $\mathrm{Ca}^{2+}$ waves) can occur. ${ }^{196-199}$ This glial network afforded by $\mathrm{Cx} 43$ gap junctions is important not only in supporting neuronal activity by sustaining proper energy sources, but also in orchestrating neuronal network activity through the release of gliotransmitters such as L-glutamate in an apposing glial syncytium. ${ }^{200}$ Under neuropathological conditions, there is a shift in either Cx43 expression or in cellular localization (or both), and glial communication through the syncytium is stunted. ${ }^{201}$ This change in astrocyte coupling can be either beneficial or detrimental, an effect that is likely diseaseand context-dependent. Nevertheless, astrocyte $\mathrm{Cx} 43$ will likely be a good target to consider modulating, with the goal of ameliorating the neuropathology in specific instances or contexts of neurological diseases and disorders. For extensive review on this topic, see Giaume et al. ${ }^{200}$ and Kielian. ${ }^{202}$

Potassium channels. The role of astrocyte inwardly rectifying $\mathrm{K}^{+}$channels ( $\mathrm{K}_{\mathrm{ir}}$ channels) with regard to brain function has been nicely and thoroughly reviewed. ${ }^{203}$ In brief, $K_{\text {ir }}$ channels are localized to astrocyte end-feet and are responsible for maintaining the resting membrane potential of astrocytes, needed for proper $\mathrm{K}^{+}$buffering. ${ }^{203}$ Given that the predominant astrocyte $\mathrm{K}_{\mathrm{ir}}$ channel $\mathrm{K}_{\mathrm{ir}} 4.1$ is highly regulated, and that its expression or activity (or both) decrease upon injury, inflammation, or disease, it seems reasonable to attempt to enhance its activity or expression as a potential therapeutic target.

Arundic acid. Although the precise molecular target or targets of arundic acid (ONO-2506) remain elusive, it is reported to target changes in astrocyte gene expression while also ameliorating several neurological diseases and disorders in rodent models. Notably, in vitro, the neuroprotective effect of arundic acid on neurons in culture required the presence of astrocytes. In vivo, astrogliosis as measured via GFAP immunoreactiv- 
ity is reduced by arundic acid in a mouse model of Alzheimer's disease $\left(\mathrm{APP}_{\mathrm{sw}}\right.$ transgenic mice $),{ }^{204}$ as well as in mice subjected to MPTP-mediated neurotoxicity. ${ }^{205}$ Notably, treatment with arundic acid resulted in amelioration of the pathology associated with the aforementioned mouse model ${ }^{204,205}$ and in mice subjected to a permanent focal ischemia. ${ }^{206}$ Although the mechanism or mechanisms for these beneficial effects remain unknown, studies have speculated that they may involve astrocyte-specific functions, including modulation of glutamate transporter (increased) and S-100B (decreased) expression. More research will be necessary to fully elucidate whether this compound does target astrocytes and, if so, what molecular mechanisms might be involved.

\section{CELL DELIVERY}

It deserves brief mention that transplantation strategies involving astrocytes are also under investigation. For example, grafts of stem or progenitor cells that mature into healthy astrocytes are reported to improve outcome in a mouse model of ALS in which host astrocytes are abnormal and express a mutant SOD. ${ }^{73}$ A different strategy uses grafts of astrocytes that are genetically modified to produce specific molecules, such as growth factors, as therapeutic pumps to deliver those molecules in specific locations. ${ }^{207,208}$ Such grafts of genetically modified astrocytes may be able to provide long-term, locally restricted delivery of therapeutic molecules via cells that integrate into the neural parenchyma both structurally and functionally.

\section{CONCLUSION}

Reactive astrogliosis is emerging as a complex and multifaceted process that can range from subtle and reversible alterations in gene expression and morphology to the pronounced and long-lasting changes associated with scar formation. The responses of reactive astrocytes to CNS insults are controlled in a context-dependent manner by specific signaling mechanisms that mediate numerous essential beneficial functions, but under certain circumstances can lead to harmful effects. The simplistic but widely held notions that reactive astrogliosis and scar formation are maladaptive responses and that complete blockade of reactive astrogliosis per se will be beneficial, are no longer tenable. Big-picture functions of reactive astrogliosis and scar formation include protecting neural cells, tissue and function, and restricting the spread of inflammation and infection. Dysfunctions of reactive astrogliosis and scar formation have the potential to contribute to, or to be primary causes of, CNS disease mechanisms, either through loss of normal functions or through gain of detrimental effects. Accordingly, therapeutic strategies will need to be directed at specific aspects of reactive astrogliosis and specific molecular mechanisms that may be augmented or attenuated for specific purposes. In this regard, it will be important to elucidate the many potential biological functions of specific molecules, including potential cross-talk between different cellular signaling and other pathways. Even well thought-out therapeutic targets could have unexpected ill-effects, which highlights the need to further unravel the basic science underlying potential therapeutic targets.

Acknowledgments: This work was supported in part by U.S. National Institutes of Health-National Institute of Neurological Disorders and Stroke (NIH-NINDS) grant NS057624 (M.V.S.), NIH grant T32-MH19925 through the Cousins Center for Psychoneuroimmunology at UCLA (M.E.H.), the Wing's for Life Charitable Foundation (M.V.S.), and the National Multiple Sclerosis Society (M.V.S.).

\section{REFERENCES}

1. Barres BA. The mystery and magic of glia: a perspective on their roles in health and disease. Neuron 2008;60:430-440.

2. Nedergaard M, Ransom B, Goldman SA. New roles for astrocytes: redefining the functional architecture of the brain. Trends Neurosci 2003;26:523-530.

3. Pellerin L, Bouzier-Sore AK, Aubert A, et al. Activity-dependent regulation of energy metabolism by astrocytes: an update. Glia 2007;55:1251-1262.

4. Seifert G, Schilling K, Steinhäuser C. Astrocyte dysfunction in neurological disorders: a molecular perspective. Nat Rev Neurosci 2006;7:194-206.

5. Sofroniew MV, Vinters HV. Astrocytes: biology and pathology. Acta Neuropathol 2010;119:7-35.

6. Pekny M, Nilsson M. Astrocyte activation and reactive gliosis. Glia 2005;50:427-434.

7. Sofroniew MV. Molecular dissection of reactive astrogliosis and glial scar formation. Trends Neurosci 2009;32:638-647.

8. Sofroniew MV. Reactive astrocytes in neural repair and protection. Neuroscientist 2005;5:400-407.

9. Darlington CL. Astrocytes as targets for neuroprotective drugs. Curr Opin Investig Drugs 2005;6:700-703.

10. Fuller S, Münch G, Steele M. Activated astrocytes: a therapeutic target in Alzheimer's disease? Expert Rev Neurother 2009;9: $1585-1594$.

11. Sofroniew MV. Astrocyte failure as a cause of CNS dysfunction. Mol Psychiatry 2000;5:230-232.

12. Rothstein JD, Dykes-Hoberg M, Pardo CA, et al. Knockout of glutamate transporters reveals a major role for astroglial transport in excitotoxicity and clearance of glutamate. Neuron 1996; 16:675-686.

13. Bush TG, Puvanachandra N, Horner CH, et al. Leukocyte infiltration, neuronal degeneration, and neurite outgrowth after ablation of scar-forming, reactive astrocytes in adult transgenic mice. Neuron 1999;23:297-308.

14. Swanson RA, Ying W, Kauppinen TM. Astrocyte influences on ischemic neuronal death. Curr Mol Med 2004;4:193-205.

15. Chen Y, Vartiainen NE, Ying W, Chan PH, Koistinaho J, Swanson RA. Astrocytes protect neurons from nitric oxide toxicity by a glutathione-dependent mechanism. J Neurochem 2001;77: 1601-1610.

16. Shih AY, Johnson DA, Wong G, et al. Coordinate regulation of glutathione biosynthesis and release by Nrf2-expressing glia potently protects neurons from oxidative stress. J Neurosci 2003;23:3394-3406.

17. Vargas MR, Johnson DA, Sirkis DW, Messing A, Johnson JA. $\mathrm{Nrf} 2$ activation in astrocytes protects against neurodegeneration 
in mouse models of familial amyotrophic lateral sclerosis. J Neurosci 2008;28:13574-13581.

18. Sarafian TA, Montes C, Imura T, et al. Disruption of astrocyte STAT3 signaling decreases mitochondrial function and increases oxidative stress in vitro. PLoS One 2010;5:e9532.

19. Lin JH, Lou N, Kang N, et al. A central role of connexin 43 in hypoxic preconditioning. J Neurosci 2008;28:681-695.

20. Rao KV, Panickar KS, Jayakumar AR, Norenberg MD. Astrocytes protect neurons from ammonia toxicity. Neurochem Res 2005;30:1311-1318.

21. Koistinaho M, Lin S, Wu X, et al. Apolipoprotein E promotes astrocyte colocalization and degradation of deposited amyloid- $\beta$ peptides. Nat Med 2004;10:719-726.

22. Zador Z, Stiver S, Wang V, Manley GT. Role of aquaporin-4 in cerebral edema and stroke. Handb Exp Pharmacol 2009;190: $159-170$.

23. Faulkner JR, Herrmann JE, Woo MJ, Tansey KE, Doan NB, Sofroniew MV. Reactive astrocytes protect tissue and preserve function after spinal cord injury. J Neurosci 2004;24:2143-2155.

24. Myer DJ, Gurkoff GG, Lee SM, Hovda DA, Sofroniew MV. Essential protective roles of reactive astrocytes in traumatic brain injury. Brain 2006;129:2761-2772.

25. Herrmann JE, Imura T, Song B, et al. STAT3 is a critical regulator of astrogliosis and scar formation after spinal cord injury. J Neurosci 2008;28:7231-7243.

26. Li L, Lundkvist A, Andersson D, et al. Protective role of reactive astrocytes in brain ischemia. J Cereb Blood Flow Metab 2008; 28:468-481.

27. Okada S, Nakamura M, Katoh H, et al. Conditional ablation of Stat 3 or Socs 3 discloses a dual role for reactive astrocytes after spinal cord injury. Nat Med 2006;12:829-834.

28. Drogemuller K, Helmuth U, Brunn A, et al. Astrocyte gp130 expression is critical for the control of Toxoplasma encephalitis. J Immunol 2008;181:2683-2693.

29. Voskuhl RR, Peterson RS, Song B, et al. Reactive astrocytes form scar-like perivascular barriers to leukocytes during adaptive immune inflammation of the CNS. J Neurosci 2009;29: $11511-11522$.

30. Maragakis NJ, Rothstein JD. Mechanisms of disease: astrocytes in neurodegenerative disease. Nat Clin Pract Neurol 2006;2: $679-689$.

31. Sattler R, Rothstein JD. Regulation and dysregulation of glutamate transporters. Handb Exp Pharmacol 2006;(175):277-303.

32. Dabir DV, Robinson MB, Swanson E, et al. Impaired glutamate transport in a mouse model of tau pathology in astrocytes. J Neurosci 2006;26:644-654.

33. Li LB, Toan SV, Zelenaia O, et al. Regulation of astrocytic glutamate transporter expression by Akt: evidence for a selective transcriptional effect on the GLT-1/EAAT2 subtype. J Neurochem 2006;97:759-771.

34. Rothstein JD, Martin LJ, Kuncl RW. Decreased glutamate transport by the brain and spinal cord in amyotrophic lateral sclerosis. N Engl J Med 1992;326:1464-1468.

35. Fontana AC, de Oliveira Beleboni R, Wojewodzic MW, et al. Enhancing glutamate transport: mechanism of action of Parawixin1, a neuroprotective compound from Parawixia bistriata spider venom. Mol Pharmacol 2007;72:1228-1237.

36. Fontana AC, Guizzo R, de Oliveira Beleboni R, et al. Purification of a neuroprotective component of Parawixia bistriata spider venom that enhances glutamate uptake. Br J Pharmacol 2003; 139:1297-1309.

37. Rothstein JD, Patel S, Regan MR, et al. $\beta$-Lactam antibiotics offer neuroprotection by increasing glutamate transporter expression. Nature 2005;433:73-77.

38. Pascuzzi RM, Shefner J, Chappell AS, et al. A phase II trial of talampanel in subjects with amyotrophic lateral sclerosis. Amyotroph Lateral Scler 2010;11:266-271.

39. Cornell-Bell AH, Finkbeiner SM, Cooper MS, Smith SJ. Glutamate induces calcium waves in cultured astrocytes: long-range glial signaling. Science 1990;247:470-473.
40. Wang X, Takano T, Nedergaard M. Astrocytic calcium signaling: mechanism and implications for functional brain imaging. Methods Mol Biol 2009;489:93-109.

41. Shigetomi E, Kracun S, Sofroniew MV, Khakh BS. A genetically targeted optical sensor to monitor calcium signals in astrocyte processes. Nat Neurosci 2010;13:759-766.

42. Halassa MM, Haydon PG. Integrated brain circuits: astrocytic networks modulate neuronal activity and behavior. Annu Rev Physiol 2010;72:335-355.

43. Henneberger C, Papouin T, Oliet SH, Rusakov DA. Long-term potentiation depends on release of D-serine from astrocytes. Nature 2010;463:232-236.

44. Shigetomi E, Bowser DN, Sofroniew MV, Khakh BS. Two forms of astrocyte calcium excitability have distinct effects on NMDA receptor-mediated slow inward currents in pyramidal neurons. J Neurosci 2008;28:6659-6663.

45. Hamby ME, Hewett JA, Hewett SJ. TGF- $\beta 1$ reduces the heterogeneity of astrocytic cyclooxygenase- 2 and nitric oxide synthase-2 gene expression in a stimulus-independent manner. Prostaglandins Other Lipid Mediat 2008;85:115-124.

46. Hewett SJ, Csernansky CA, Choi DW. Selective potentiation of NMDA-induced neuronal injury following induction of astrocytic iNOS. Neuron 1994;13:487-494.

47. Katsuse O, Iseki E, Kosaka K. Immunohistochemical study of the expression of cytokines and nitric oxide synthases in brains of patients with dementia with Lewy bodies. Neuropathology 2003;23:9-15.

48. Lieb K, Engels S, Fiebich BL. Inhibition of LPS-induced iNOS and NO synthesis in primary rat microglial cells. Neurochem Int 2003;42:131-137.

49. Tran EH, Hardin-Pouzet H, Verge G, Owens T. Astrocytes and microglia express inducible nitric oxide synthase in mice with experimental allergic encephalomyelitis. J Neuroimmunol 1997; 74:121-129.

50. Liberatore GT, Jackson-Lewis V, Vukosavic S, et al. Inducible nitric oxide synthase stimulates dopaminergic neurodegeneration in the MPTP model of Parkinson disease. Nat Med 1999; 5:1403-1409.

51. Pozza M, Bettelli C, Aloe L, Giardino L, Calzà L. Further evidence for a role of nitric oxide in experimental allergic encephalomyelitis: aminoguanidine treatment modifies its clinical evolution. Brain Res 2000;855:39-46.

52. Smith KJ, Lassmann H. The role of nitric oxide in multiple sclerosis. Lancet Neurol 2002;1:232-241.

53. Iadecola C, Zhang F, Casey R, Nagayama M, Ross ME. Delayed reduction of ischemic brain injury and neurological deficits in mice lacking the inducible nitric oxide synthase gene. J Neurosci 1997; 17:9157-9164.

54. Iadecola C, Zhang F, Xu X. Inhibition of inducible nitric oxide synthase ameliorates cerebral ischemic damage. Am J Physiol 1995;268:R286-R292.

55. Shin T, Kim S, Moon C, Wie M, Kim H. Aminoguanidineinduced amelioration of autoimmune encephalomyelitis is mediated by reduced expression of inducible nitric oxide synthase in the spinal cord. Immunol Invest 2000;29:233-241.

56. Shin T, Tanuma N, Kim S, et al. An inhibitor of inducible nitric oxide synthase ameliorates experimental autoimmune myocarditis in Lewis rats. J Neuroimmunol 1998;92:133-138.

57. Iadecola C, Li J, Ebner TJ, Xu X. Nitric oxide contributes to functional hyperemia in cerebellar cortex. Am J Physiol 1995; 268:R1153-R1162.

58. Nathan C, Calingasan N, Nezezon J, et al. Protection from Alzheimer's-like disease in the mouse by genetic ablation of inducible nitric oxide synthase. J Exp Med 2005;202:11631169.

59. Lei SZ, Pan ZH, Aggarwal SK, et al. Effect of nitric oxide production on the redox modulatory site of the NMDA receptorchannel complex. Neuron 1992;8:1087-1099.

60. Colton CA, Vitek MP, Wink DA, et al. NO synthase 2 (NOS2) deletion promotes multiple pathologies in a mouse model of Alzheimer's disease. Proc Natl Acad Sci U S A 2006;103: 12867-12872.

61. Lipton SA, Choi YB, Pan ZH, et al. A redox-based mecha- 
nism for the neuroprotective and neurodestructive effects of nitric oxide and related nitroso-compounds. Nature 1993;364: 626-632.

62. Vidwans AS, Kim S, Coffin DO, Wink DA, Hewett SJ. Analysis of the neuroprotective effects of various nitric oxide donor compounds in murine mixed cortical cell culture. J Neurochem 1999;72:1843-1852.

63. Szabo C, Zingarelli B, O'Connor M, Salzman AL. DNA strand breakage, activation of poly (ADP-ribose) synthetase, and cellular energy depletion are involved in the cytotoxicity of macrophages and smooth muscle cells exposed to peroxynitrite. Proc Natl Acad Sci U S A 1996;93:1753-1758.

64. Zingarelli B, O’Connor M, Wong H, Salzman AL, Szabó C. Peroxynitrite-mediated DNA strand breakage activates poly-adenosine diphosphate ribosyl synthetase and causes cellular energy depletion in macrophages stimulated with bacterial lipopolysaccharide. J Immunol 1996;156:350-358.

65. Hewett SJ, Muir JK, Lobner D, Symons A, Choi DW. Potentiation of oxygen-glucose deprivation-induced neuronal death after induction of iNOS. Stroke 1996;27:1586-1591.

66. Vidwans AS, Hewett SJ. Enhanced release of synaptic glutamate underlies the potentiation of oxygen-glucose deprivation-induced neuronal injury after induction of NOS-2. Exp Neurol 2004;190:91-101.

67. Koehler RC, Roman RJ, Harder DR. Astrocytes and the regulation of cerebral blood flow. Trends Neurosci 2009;32:160169.

68. Barber SC, Shaw PJ. Oxidative stress in ALS: key role in motor neuron injury and therapeutic target. Free Radic Biol Med 2010; 48:629-641.

69. Ilieva H, Polymenidou M, Cleveland DW. Non-cell autonomous toxicity in neurodegenerative disorders: ALS and beyond. J Cell Biol 2009; 187:761-772.

70. Yamanaka K, Chun SJ, Boillee S, et al. Astrocytes as determinants of disease progression in inherited amyotrophic lateral sclerosis. Nat Neurosci 2008;11:251.

71. Rothstein JD, Van Kammen M, Levey AI, Martin LJ, Kuncl RW. Selective loss of glial glutamate transporter GLT-1 in amyotrophic lateral sclerosis. Ann Neurol 1995;38:73-84.

72. Bruijn LI, Becher MW, Lee MK, et al. ALS-linked SOD1 mutant G85R mediates damage to astrocytes and promotes rapidly progressive disease with SOD1-containing inclusions. Neuron 1997; 18:327-338.

73. Lepore AC, Rauck B, Dejea C, et al. Focal transplantation-based astrocyte replacement is neuroprotective in a model of motor neuron disease. Nat Neurosci 2008;11:1294-1301.

74. Lleo A, Galea E, Sastre M. Molecular targets of non-steroidal anti-inflammatory drugs in neurodegenerative diseases. Cell Mol Life Sci 2007;64:1403-1418.

75. Asanuma M, Miyazaki I. Nonsteroidal anti-inflammatory drugs in Parkinson's disease: possible involvement of quinone formation. Expert Rev Neurotherapeutics 2006;6:1313-1325.

76. Heneka MT, Sastre M, Dumitrescu-Ozimek L, et al. Acute treatment with the PPAR $\gamma$ agonist pioglitazone and ibuprofen reduces glial inflammation and A $\beta 1-42$ levels in APPV717I transgenic mice. Brain 2005;128:1442-1453.

77. Drachman DB, Frank K, Dykes-Hoberg M, et al. Cyclooxygenase 2 inhibition protects motor neurons and prolongs survival in a transgenic mouse model of ALS. Ann Neurol 2002;52:771778.

78. Bae MK, Kim SR, Lee HJ, et al. Aspirin-induced blockade of NF- $\kappa \mathrm{B}$ activity restrains up-regulation of glial fibrillary acidic protein in human astroglial cells. Biochim Biophys Acta 2006; 1763:282-289.

79. Dringen R, Hirrlinger J Glutathione pathways in the brain. Biol Chem 2003;384:505-516.

80. Bush TG, Savidge TC, Freeman TC, et al. Fulminant jejunoileitis following ablation of enteric glia in adult transgenic mice. Cell 1998;93:189-201.

81. Savidge TC, Newman P, Pothoulakis C, et al. Enteric glia regulate intestinal barrier function and inflammation via release of $S$-nitrosoglutathione. Gastroenterology 2007;132:1344-1358.

82. Hamby ME, Hewett JA, Hewett SJ. TGF- $\beta 1$ potentiates astro- cytic nitric oxide production by expanding the population of astrocytes that express NOS-2. Glia 2006;54:566-577.

83. Hewett SJ. Interferon-gamma reduces cyclooxygenase-2-mediated prostaglandin E2 production from primary mouse astrocytes independent of nitric oxide formation. J Neuroimmunol 1999;94:134-143.

84. Hewett SJ, Corbett JA, McDaniel ML, Choi DW. Interferongamma and interleukin-1 $\beta$ induce nitric oxide formation from primary mouse astrocytes. Neurosci Lett 1993;164:229-232.

85. Hamby ME, Gragnolati AR, Hewett SJ, Hewett JA. TGF $\beta 1$ and $\mathrm{TNF} \alpha$ potentiate nitric oxide production in astrocyte cultures by recruiting distinct subpopulations of cells to express NOS-2. Neurochem Int 2008;52:962-971.

86. Minghetti L, Polazzi E, Nicolini A, Levi G. Opposite regulation of prostaglandin E2 synthesis by transforming growth factor- $\beta 1$ and interleukin 10 in activated microglial cultures. J Neuroimmunol 1998;82:31-39.

87. Saad B, Constam DB, Ortmann R, Moos M, Fontana A, Schachner M. Astrocyte-derived TGF- $\beta 2$ and NGF differentially regulate neural recognition molecule expression by cultured astrocytes. J Cell Biol 1991;115:473-484.

88. Krieglstein K, Reuss B, Maysinger D, Unsicker K. Short communication: transforming growth factor- $\beta$ mediates the neurotrophic effect of fibroblast growth factor- 2 on midbrain dopaminergic neurons. Eur J Neurosci 1998;10:2746-2750.

89. Villoslada P, Genain CP. Role of nerve growth factor and other trophic factors in brain inflammation. Prog Brain Res 2004;146: 403-414.

90. Ridet JL, Malhotra SK, Privat A, Gage FH. Reactive astrocytes: cellular and molecular cues to biological function. Trends Neurosci 1997;20:570-577.

91. Mena MA, García de Yébenes J. Glial cells as players in parkinsonism: the "good," the "bad," and the "mysterious" glia. Neuroscientist 2008;14:544-560.

92. Ishibashi T, Dakin KA, Stevens B, et al. Astrocytes promote myelination in response to electrical impulses. Neuron 2006;49: $823-832$.

93. Lindholm D, Castrén E, Kiefer R, Zafra F, Thoenen H. Transforming growth factor- $\beta 1$ in the rat brain: increase after injury and inhibition of astrocyte proliferation. J Cell Biol 1992;117: $395-400$.

94. Wang X, Yue TL, White RF, Barone FC, Feuerstein GZ. Transforming growth factor- $\beta 1$ exhibits delayed gene expression following focal cerebral ischemia. Brain Res Bull 1995;36:607609.

95. Krupinski J, Kumar P, Kumar S, Kaluza J. Increased expression of TGF- $\beta 1$ in brain tissue after ischemic stroke in humans. Stroke 1996;27:852-857.

96. Ata AK, Funa K, Olsson Y. Expression of various TGF- $\beta$ isoforms and type I receptor in necrotizing human brain lesions. Acta Neuropathol 1997;93:326-333.

97. Ali $\mathrm{C}$, Docagne $\mathrm{F}$, Nicole $\mathrm{O}$, et al. Increased expression of transforming growth factor- $\beta$ after cerebral ischemia in the baboon: an endogenous marker of neuronal stress? J Cereb Blood Flow Metab 2001;21:820-827.

98. Zetterberg H, Andreasen N, Blennow K. Increased cerebrospinal fluid levels of transforming growth factor- $\beta 1$ in Alzheimer's disease. Neurosci Lett 2004;367:194-196.

99. Kiefer R, Streit WJ, Toyka KV, Kreutzberg GW, Hartung HP. Transforming growth factor- $\beta 1$ : a lesion-associated cytokine of the nervous system. Int J Dev Neurosci 1995;13:331-339.

100. Kiefer R, Lindholm D, Kreutzberg GW. Interleukin-6 and transforming growth factor- $\beta 1$ mRNAs are induced in rat facial nucleus following motoneuron axotomy. Eur J Neurosci 1993; 5:775-781.

101. Knuckey NW, Finch P, Palm DE, et al. Differential neuronal and astrocytic expression of transforming growth factor $\beta$ isoforms in rat hippocampus following transient forebrain ischemia. Brain Res Mol Brain Res 1996;40:1-14.

102. Morgan TE, Nichols NR, Pasinetti GM, Finch CE. TGF- $\beta 1$ mRNA increases in macrophage/microglial cells of the hippocampus in response to deafferentation and kainic acid-induced neurodegeneration. Exp Neurol 1993;120:291-301. 
103. Wahl SM, Allen JB, McCartney-Francis N, et al. Macrophageand astrocyte-derived transforming growth factor $\beta$ as a mediator of central nervous system dysfunction in acquired immune deficiency syndrome. J Exp Med 1991;173:981-991.

104. Krupinski J, Vodovotz Y, Li C, et al. Inducible nitric oxide production and expression of transforming growth factor- $\beta 1$ in serum and CSF after cerebral ischaemic stroke in man. Nitric Oxide 1998;2:442-453.

105. Morganti-Kossmann MC, Hans VH, Lenzlinger PM, et al. TGF- $\beta$ is elevated in the CSF of patients with severe traumatic brain injuries and parallels blood-brain barrier function. J Neurotrauma 1999;16:617-628.

106. Huang CC, Chang YC, Chow NH, Wang ST. Level of transforming growth factor $\beta 1$ is elevated in cerebrospinal fluid of children with acute bacterial meningitis. J Neurol 1997;244: $634-638$.

107. De Groot CJ, Montagne L, Barten AD, Sminia P, Van Der Valk P. Expression of transforming growth factor (TGF)- $\beta 1,-\beta 2$, and $-\beta 3$ isoforms and TGF- $\beta$ type I and type II receptors in multiple sclerosis lesions and human adult astrocyte cultures. J Neuropathol Exp Neurol 1999;58:174-187.

108. Peress NS, Perillo E, Seidman RJ. Glial transforming growth factor (TGF)- $\beta$ isotypes in multiple sclerosis: differential glial expression of TGF- $\beta 1,2$ and 3 isotypes in multiple sclerosis. J Neuroimmunol 1996;71:115-123.

109. Vawter MP, Dillon-Carter O, Tourtellotte WW, Carvey P, Freed WJ. TGF $\beta 1$ and TGF $\beta 2$ concentrations are elevated in Parkinson's disease in ventricular cerebrospinal fluid. Exp Neurol 1996;142:313-322.

110. Miyazawa K, Shinozaki M, Hara T, Furuya T, Miyazono K. Two major Smad pathways in TGF- $\beta$ superfamily signalling. Genes Cells 2002;7:1191-1204.

111. Dhandapani KM, Brann DW. Transforming growth factor- $\beta$ : a neuroprotective factor in cerebral ischemia. Cell Biochem Biophys 2003;39:13-22.

112. Buisson A, Lesné S, Docagne F, et al. Transforming growth factor- $\beta$ and ischemic brain injury. Cell Mol Neurobiol 2003; 23:539-550.

113. Boche D, Cunningham C, Gauldie J, Perry VH. Transforming growth factor- $\beta 1$-mediated neuroprotection against excitotoxic injury in vivo. J Cereb Blood Flow Metab 2003;23:1174-1182.

114. Henrich-Noack P, Prehn JH, Krieglstein J. TGF- $\beta 1$ protects hippocampal neurons against degeneration caused by transient global ischemia. Dose-response relationship and potential neuroprotective mechanisms. Stroke 1996;27:1609-1614; discussion 1615 .

115. Prehn JH, Backhauss C, Krieglstein J. Transforming growth factor- $\beta 1$ prevents glutamate neurotoxicity in rat neocortical cultures and protects mouse neocortex from ischemic injury in vivo. J Cereb Blood Flow Metab 1993;13:521-525.

116. Brionne TC, Tesseur I, Masliah E, Wyss-Coray T. Loss of TGF- $\beta 1$ leads to increased neuronal cell death and microgliosis in mouse brain. Neuron 2003;40:1133-1145.

117. Wyss-Coray T, Borrow P, Brooker MJ, Mucke L. Astroglial overproduction of TGF- $\beta 1$ enhances inflammatory central nervous system disease in transgenic mice. J Neuroimmunol 1997; $77: 45-50$.

118. Wyss-Coray T, Masliah E, Mallory M, et al. Amyloidogenic role of cytokine TGF- $\beta 1$ in transgenic mice and in Alzheimer's disease. Nature 1997;389:603-606.

119. Wyss-Coray T, Feng L, Masliah E, et al. Increased central nervous system production of extracellular matrix components and development of hydrocephalus in transgenic mice overexpressing transforming growth factor- $\beta 1$. Am J Pathol 1995; 147: 53-67.

120. Lesné S, Docagne F, Gabriel C, et al. Transforming growth factor- $\beta 1$ potentiates amyloid- $\beta$ generation in astrocytes and in transgenic mice. J Biol Chem 2003;278:18408-18418.

121. Burton T, Liang B, Dibrov A, Amara F. Transcriptional activation and increase in expression of Alzheimer's $\beta$-amyloid precursor protein gene is mediated by TGF- $\beta$ in normal human astrocytes. Biochem Biophys Res Commun 2002;295:702-712.

122. Burton T, Liang B, Dibrov A, Amara F. Transforming growth factor- $\beta$-induced transcription of the Alzheimer $\beta$-amyloid precursor protein gene involves interaction between the CTCF-complex and Smads. Biochem Biophys Res Commun 2002;295:713-723.

123. Johns LD, Flanders KC, Ranges GE, Sriram S. Successful treatment of experimental allergic encephalomyelitis with transforming growth factor- $\beta 1$. J Immunol 1991;147:1792-1796.

124. Amara FM, Junaid A, Clough RR, Liang B. TGF- $\beta_{1}$, regulation of Alzheimer amyloid precursor protein mRNA expression in a normal human astrocyte cell line: mRNA stabilization. Brain Res Mol Brain Res 1999;71:42-49.

124a. Smith GM, Strunz C. Growth factor and cytokine regulation of chondroitin sulfate proteoglycans by astrocytes. Glia 2005;52: 209-218.

125. Wang Y, Moges H, Bharucha Y, Symes A. Smad3 null mice display more rapid wound closure and reduced scar formation after a stab wound to the cerebral cortex. Exp Neurol 2007;203: $168-184$.

126. da Cunha A, Jefferson JA, Jackson RW, Vitković L. Glial cellspecific mechanisms of TGF- $\beta 1$ induction by IL- 1 in cerebral cortex. J Neuroimmunol 1993;42:71-85.

127. Vivien D, Bernaudin M, Buisson A, Divoux D, MacKenzie ET, Nouvelot A. Evidence of type I and type II transforming growth factor- $\beta$ receptors in central nervous tissues: changes induced by focal cerebral ischemia. J Neurochem 1998;70:2296-2304.

128. Pratt BM, McPherson JM. TGF- $\beta$ in the central nervous system: potential roles in ischemic injury and neurodegenerative diseases. Cytokine Growth Factor Rev 1997;8:267-292.

129. Flanders KC, Ren RF, Lippa CF. Transforming growth factorbetas in neurodegenerative disease. Prog Neurobiol 1998;54: $71-85$.

130. König HG, Kögel D, Rami A, Prehn JH. TGF- $\beta 1$ activates two distinct type I receptors in neurons: implications for neuronal NF- $\kappa$ B signaling. J Cell Biol 2005;168:1077-1086.

131. Lux A, Salway F, Dressman HK, et al. ALK1 signalling analysis identifies angiogenesis related genes and reveals disparity between TGF- $\beta$ and constitutively active receptor induced gene expression. BMC Cardiovasc Disord 2006;6:13.

132. Le Y, Iribarren P, Gong W, Cui Y, Zhang X, Wang JM. TGF- $\beta 1$ disrupts endotoxin signaling in microglial cells through Smad3 and MAPK pathways. J Immunol 2004;173:962-968.

133. Hamby ME, Hewett JA, Hewett SJ. Smad3-dependent signaling underlies the TGF- $\beta 1$-mediated enhancement in astrocytic iNOS expression. Glia 2010;58:1282-1891.

134. Spooren A, Kooijman R, Lintermans B, et al. Cooperation of $\mathrm{NF} \kappa \mathrm{B}$ and CREB to induce synergistic IL-6 expression in astrocytes. Cell Signal 2010;22:871-881.

135. Fogal B, Hewett SJ. Interleukin-1 $\beta$ : a bridge between inflammation and excitotoxicity? J Neurochem 2008;106:1-23.

136. John GR, Lee SC, Song X, Rivieccio M, Brosnan CF. IL-1regulated responses in astrocytes: Relevance to injury and recovery. Glia 2005;49:161-176.

137. Brambilla R, Bracchi-Ricard V, Hu W-H, et al. Inhibition of astroglial nuclear factor $\kappa \mathrm{B}$ reduces inflammation and improves functional recovery after spinal cord injury. J Exp Med 2005; 202:145-156.

138. Saccani S, Pantano S, Natoli G. p38-Dependent marking of inflammatory genes for increased NF- $\kappa$ B recruitment. Nat Immunol 2002;3:69-75.

139. Rahman I, Marwick J, Kirkham P. Redox modulation of chromatin remodeling: impact on histone acetylation and deacetylation, NF- $\kappa \mathrm{B}$ and pro-inflammatory gene expression. Biochem Pharmacol 2004;68:1255-1267.

140. Muegge K. Preparing the target for the bullet. Nat Immunol 2002;3:16-17.

141. Saccani S, Pantano S, Natoli G. Two waves of nuclear factor $\kappa$ B recruitment to target promoters. J Exp Med 2001;193:13511359.

142. Natoli G, Saccani S, Bosisio D, Marazzi I. Interactions of $N F-\kappa B$ with chromatin: the art of being at the right place at the right time. Nat Immunol 2005;6:439-445.

143. Ershler WB, Sun WH, Binkley N. The role of interleukin-6 in certain age-related diseases. Drugs Aging 1994;5:358-365. 
144. Taga T, Kishimoto T. gp130 and the interleukin- 6 family of cytokines. Annu Rev Immunol 1997;15:797-819.

145. Penkowa M, Giralt M, Lago N, et al. Astrocyte-targeted expression of IL-6 protects the CNS against a focal brain injury. Exp Neurol 2003;181:130-148.

146. Penkowa M, Camats J, Hadberg H, et al. Astrocyte-targeted expression of interleukin- 6 protects the central nervous system during neuroglial degeneration induced by 6 -aminonicotinamide. J Neurosci Res 2003;73:481-496.

147. Swartz KR, Liu F, Sewell D, et al. Interleukin-6 promotes posttraumatic healing in the central nervous system. Brain Res 2001; 896:86-95

148. Campbell IL, Abraham CR, Masliah E, et al. Neurologic disease induced in transgenic mice by cerebral overexpression of interleukin 6. Proc Natl Acad Sci U S A 1993;90:10061-10065.

149. Quintana A, Muller M, Frausto RF, et al. Site-specific production of IL-6 in the central nervous system retargets and enhances the inflammatory response in experimental autoimmune encephalomyelitis. J Immunol 2009;183:2079-2088.

150. Sriram K, Benkovic SA, Hebert MA, Miller DB, O'Callaghan JP. Induction of gp130-related cytokines and activation of JAK2/STAT3 pathway in astrocytes precedes up-regulation of glial fibrillary acidic protein in the 1-methyl-4-phenyl-1,2,3,6tetrahydropyridine model of neurodegeneration: key signaling pathway for astrogliosis in vivo? J Biol Chem 2004;279:1993619947.

151. Nakashima K, Yanagisawa M, Arakawa H, et al. Synergistic signaling in fetal brain by STAT3-Smad1 complex bridged by p300. Science 1999;284:479-482.

152. Fan G, Martinowich K, Chin MH, et al. DNA methylation controls the timing of astrogliogenesis through regulation of JAK-STAT signaling. Development 2005;132:3345-3356.

153. Herrmann JE, Imura T, Song B, et al. STAT3 is a critical regulator of astrogliosis and scar formation after spinal cord injury. J Neurosci 2008;28:7231-7243.

154. Su Z, Yuan Y, Cao L, et al. Triptolide promotes spinal cord repair by inhibiting astrogliosis and inflammation. Glia 2010; 58:901-915.

155. Gong Y, Xue B, Jiao J, Jing L, Wang X. Triptolide inhibits COX-2 expression and PGE2 release by suppressing the activity of NF- $\kappa \mathrm{B}$ and JNK in LPS-treated microglia. J Neurochem 2008;107:779-788.

156. Levison SW, Jiang FJ, Stoltzfus OK, Ducceschi MH. IL-6-type cytokines enhance epidermal growth factor-stimulated astrocyte proliferation. Glia 2000;32:328-337.

157. Gadea A, Schinelli S, Gallo V. Endothelin-1 regulates astrocyte proliferation and reactive gliosis via a JNK/c-Jun signaling pathway. J Neurosci 2008;28:2394-2408.

158. Khakh BS, North RA. P2X receptors as cell-surface ATP sensors in health and disease. Nature 2006;442:527-532.

159. Bowser DN, Khakh BS. Vesicular ATP is the predominant cause of intercellular calcium waves in astrocytes. J Gen Physiol 2007; 129:485-491.

160. Halassa MM, Fellin T, Haydon PG. Tripartite synapses: roles for astrocytic purines in the control of synaptic physiology and behavior. Neuropharmacology 2009;57:343-346.

161. Neary JT, Kang Y, Shi YF. Signaling from nucleotide receptors to protein kinase cascades in astrocytes. Neurochem Res 2004; 29:2037-2042.

162. Neary JT, Kang Y, Willoughby KA, Ellis EF. Activation of extracellular signal-regulated kinase by stretch-induced injury in astrocytes involves extracellular ATP and P2 purinergic receptors. J Neurosci 2003;23:2348-2356.

163. Wanner IB, Deik A, Torres M, et al. A new in vitro model of the glial scar inhibits axon growth. Glia 2008;56:1691-1709.

164. Wang X, Arcuino G, Takano T, et al. P2X7 receptor inhibition improves recovery after spinal cord injury. Nat Med 2004;10: $821-827$

165. Peng W, Cotrina ML, Han X, et al. Systemic administration of an antagonist of the ATP-sensitive receptor P2X7 improves recovery after spinal cord injury. Proc Natl Acad Sci U S A 2009;106:12489-12493.
166. Urdinguio RG, Sanchez-Mut JV, Esteller M. Epigenetic mechanisms in neurological diseases: genes, syndromes, and therapies. Lancet Neurol 2009;8:1056-1072.

166a. Hamby ME, Coskun V, Sun YE. Transcriptional regulation of neuronal differentiation: the epigenetic layer of complexity. Biochim Biophys Acta 2008;1779:432-437.

167. Camelo S, Iglesias AH, Hwang D, et al. Transcriptional therapy with the histone deacetylase inhibitor trichostatin A ameliorates experimental autoimmune encephalomyelitis. J Neuroimmunol 2005;164:10-21.

168. Kim HJ, Rowe M, Ren M, Hong JS, Chen PS, Chuang DM Histone deacetylase inhibitors exhibit anti-inflammatory and neuroprotective effects in a rat permanent ischemic model of stroke: multiple mechanisms of action. J Pharmacol Exp Ther 2007:321:892-901.

169. Faraco G, Pancani T, Formentini L, et al. Pharmacological inhibition of histone deacetylases by suberoylanilide hydroxamic acid specifically alters gene expression and reduces ischemic injury in the mouse brain. Mol Pharmacol 2006;70:1876-1884.

170. Ren M, Leng Y, Jeong M, Leeds PR, Chuang DM. Valproic acid reduces brain damage induced by transient focal cerebral ischemia in rats: potential roles of histone deacetylase inhibition and heat shock protein induction. J Neurochem 2004;89:1358-1367.

171. Chen PS, Peng GS, Li G, et al. Valproate protects dopaminergic neurons in midbrain neuron/glia cultures by stimulating the release of neurotrophic factors from astrocytes. Mol Psychiatry 2006;11:1116-1125.

172. Faraco G, Pittelli M, Cavone L, et al. Histone deacetylase (HDAC) inhibitors reduce the glial inflammatory response in vitro and in vivo. Neurobiol Dis 2009;36:269-279.

173. Suh HS, Choi S, Khattar P, Choi N, Lee SC. Histone deacetylase inhibitors suppress the expression of inflammatory and innate immune response genes in human microglia and astrocytes. J Neuroimmune Pharmacol 2010 Feb 17 [Epub ahead of print].

174. Morland C, Boldingh KA, Iversen EG, Hassel B. Valproate is neuroprotective against malonate toxicity in rat striatum: an association with augmentation of high-affinity glutamate uptake. J Cereb Blood Flow Metab 2004;24:1226-1234.

175. Perisic T, Zimmermann N, Kirmeier T, et al. Valproate and amitriptyline exert common and divergent influences on global and gene promoter-specific chromatin modifications in rat primary astrocytes. Neuropsychopharmacology 2009;35:792-805.

176. Trinka $\mathrm{E}$. The use of valproate and new antiepileptic drugs in status epilepticus. Epilepsia 2007;48 Suppl 8:49-51.

177. Michaelis M, Doerr HW, Cinatl J Jr. Valproic acid as anticancer drug. Curr Pharm Des 2007;13:3378-3393.

178. Langley B, Gensert JM, Beal MF, Ratan RR. Remodeling chromatin and stress resistance in the central nervous system: histone deacetylase inhibitors as novel and broadly effective neuroprotective agents. Curr Drug Targets CNS Neurol Disord 2005;4: $41-50$.

179. Kazantsev AG, Thompson LM. Therapeutic application of histone deacetylase inhibitors for central nervous system disorders. Nat Rev Drug Discov 2008;7:854-868.

180. Balasubramanyam K, Varier RA, Altaf M, et al. Curcumin, a novel p300/CREB-binding protein-specific inhibitor of acetyltransferase, represses the acetylation of histone/nonhistone proteins and histone acetyltransferase-dependent chromatin transcription. J Biol Chem 2004;279:51163-51171.

181. Marcu MG, Jung YJ, Lee $S$, et al. Curcumin is an inhibitor of p300 histone acetyltransferase. Med Chem 2006;2:169-174.

182. Natarajan C, Bright JJ. Curcumin inhibits experimental allergic encephalomyelitis by blocking IL-12 signaling through Janus kinase-STAT pathway in T lymphocytes. J Immunol 2002;168: 6506-6513.

183. Laird MD, Sukumari-Ramesh S, Swift AEB, Meiler SE, Vender JR, Dhandapani KM. Curcumin attenuates cerebral edema following traumatic brain injury in mice: a possible role for aquaporin-4? J Neurochem 2010;113:637-648.

184. Lin MS, Lee YH, Chiu WT, Hung KS. Curcumin provides neuroprotection after spinal cord injury. J Surg Res 2010 Aug 5 [Epub ahead of print].

185. Zador Z, Bloch O, Yao X, Manley GT. Aquaporins: role in 
cerebral edema and brain water balance. Prog Brain Res 2007;161:185-194.

186. Kim JH, Lee YW, Park KA, Lee WT, Lee JE. Agmatine attenuates brain edema through reducing the expression of aquaporin-1 after cerebral ischemia. J Cereb Blood Flow Metab 2010;30:943-949.

187. Filippidis AS, Kalani MY, Rekate HL. Hydrocephalus and aquaporins: lessons learned from the bench. Childs Nerv Syst 2010 Jul 13 [Epub ahead of print].

188. Benarroch EE. Neuron-astrocyte interactions: partnership for normal function and disease in the central nervous system. Mayo Clinic Proceedings 2005;80:1326-1338.

189. Nag S, Manias J, Stewart D. Pathology and new players in the pathogenesis of brain edema. Acta Neuropathologica 2009;118: 197-217.

190. Lennon VA, Kryzer TJ, Pittock SJ, Verkman AS, Hinson SR. IgG marker of optic-spinal multiple sclerosis binds to the aquaporin-4 water channel. J Exp Med 2005;202:473-477.

191. Hinson SR, McKeon A, Lennon VA. Neurological autoimmunity targeting aquaporin-4. Neuroscience 2010;168:1009-1018.

192. Roemer SF, Parisi JE, Lennon VA, et al. Pattern-specific loss of aquaporin-4 immunoreactivity distinguishes neuromyelitis optica from multiple sclerosis. Brain 2007;130:1194-1205.

193. Hu W, Lucchinetti CF. The pathological spectrum of CNS inflammatory demyelinating diseases. Semin Immunopathol 2009; 31:439-453.

194. Sharma R, Fischer MT, Bauer J, et al. Inflammation induced by innate immunity in the central nervous system leads to primary astrocyte dysfunction followed by demyelination. Acta Neuropathol 2010;120:223-236.

195. Voskuhl RR, Palaszynski K. Sex hormones in experimental autoimmune encephalomyelitis: implications for multiple sclerosis. Neuroscientist 2001;7:258-270.

196. Orthmann-Murphy J, Abrams C, Scherer S. Gap junctions couple astrocytes and oligodendrocytes. J Mol Neurosci 2008;35: 101-116.

197. Dermietzel R, Hertberg EL, Kessler JA, Spray DC. Gap junctions between cultured astrocytes: immunocytochemical, molecular, and electrophysiological analysis. J Neurosci 1991;11: $1421-1432$.
198. Duffy HS, John GR, Lee SC, Brosnan CF, Spray DC. Reciprocal regulation of the junctional proteins claudin- 1 and connexin 43 by interleukin- $1 \beta$ in primary human fetal astrocytes. J Neurosci 2000;20:RC114.

199. Blomstrand F, Aberg ND, Eriksson PS, Hansson E, Rönnbäck L. Extent of intercellular calcium wave propagation is related to gap junction permeability and level of connexin-43 expression in astrocytes in primary cultures from four brain regions. Neuroscience 1999;92:255-265.

200. Giaume C, Koulakoff A, Roux L, Holcman D, Rouach N. Astroglial networks: a step further in neuroglial and gliovascular interactions. Nat Rev Neurosci 2010;11:87-89.

201. Rouach N, Avignone E, Même W, et al. Gap junctions and connexin expression in the normal and pathological central nervous system. Biol Cell 2002;94:457-475.

202. Kielian T. Glial connexins and gap junctions in CNS inflammation and disease. J Neurochem 2008;106:1000-1016.

203. Olsen ML, Sontheimer H. Functional implications for $\mathrm{K}_{\mathrm{ir}} 4.1$ channels in glial biology: from $\mathrm{K}^{+}$buffering to cell differentiation. J Neurochem 2008;107:589-601.

204. Mori T, Town T, Tan J, et al. Arundic acid ameliorates cerebral amyloidosis and gliosis in Alzheimer transgenic mice. J Pharmacol Exp Ther 2006;318:571-578.

205. Oki C, Watanabe Y, Yokoyama H, Shimoda T, Kato H, Araki T Delayed treatment with arundic acid reduces the MPTP-induced neurotoxicity in mice. Cell Mol Neurobiol 2008;28:417-430.

206. Tateishi N, Mori T, Kagamiishi Y, et al. Astrocytic activation and delayed infarct expansion after permanent focal ischemia in rats. Part II: suppression of astrocytic activation by a novel agent $(R)$-(-)-2-propyloctanoic acid (ONO-2506) leads to mitigation of delayed infarct expansion and early improvement of neurologic deficits. J Cereb Blood Flow Metab 2002;22:723-734.

207. Behrstock S, Ebert AD, Klein S, Schmitt M, Moore JM, Svendsen $\mathrm{CN}$. Lesion-induced increase in survival and migration of human neural progenitor cells releasing GDNF. Cell Transplant 2008; 17:753-762.

208. Suzuki M, McHugh J, Tork C, et al. GDNF secreting human neural progenitor cells protect dying motor neurons, but not their projection to muscle, in a rat model of familial ALS. PLoS One 2007;2:e689. 